ARTICLE

Implications of Fama-French Models and Critical Evaluation of Cost of Equity Approach in Explanation of Variations in Expected Stock Returns

\title{
Bingjing Gao*
}

Coventry University, Coventry, CV1 5FB, United Kingdom

\begin{tabular}{|c|c|}
\hline ARTICLE INFO & ABSTRACT \\
\hline Article history & CAPM theory that solves relationship between asset return and asset risk \\
\hline Received: 28 March 2020 & for potential investment project by CML and SML, is illustrated in the \\
\hline Revised: 7 April 2020 & $\begin{array}{l}\text { first section as an introduction of further analysis of corporate valuation } \\
\text { techniques. Fama and French three factor model is perceived as a revision }\end{array}$ \\
\hline Accepted: 9 April 2020 & of CAPM, although it stills has severe weaknesses. CAPM theory solves \\
\hline Published Online: 16 April 2020 & $\begin{array}{l}\text { relationship between asset return and asset risk for potential investment } \\
\text { project by CML and SML. }\end{array}$ \\
\hline
\end{tabular}

\section{CAPM}

Fama-French Models

Cost of equity

Portfolio theory

Asset pricing

\section{Capital Asset Pricing Model (CAPM) as Foundational Concepts of Portfolio Theory and Asset Pricing}

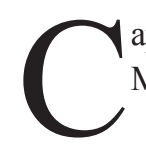

apital Asset Pricing Model (CAPM) is based on Markowitz securities investment

portfolio theory, as cornerstone of modern corporate finance by giving accurate forecast of relationship between asset risk and rate of return. CAPM theory solves relationship between asset return and asset risk for potential investment project by CML and SML. CAPM model enables us to make reasonable corporate valuation for those assets not traded in public market (Xiao et al, 2017). One of CAPM assumptions is that investors could evaluate investment portfolios reasonably according to expected rate of return and variations during a certain period (Anon, 2005). It is assumed that all investors are rational in economic sense and pursuing minimum variation of investment portfolios. CAPM also assumes that all investors tend to choose portfolios that generate higher expected rate of return. Capital market is indivisible and all investors have free access to related information given market effectiveness (Xiao et al, 2017). Assets are divisible unlimitedly and all investors could sell assets of arbitrary amount. Investors could borrow or lend at risk free rate without transaction cost and tax.

There are massive amounts of investors and each investor's wealth is marginal as for all investors' aggre-

*Corresponding Author:

Bingjing Gao,

Coventry University, Coventry, CV1 5FB, United Kingdom;

E-mail: gaobingjing1996@163.com. 
gate wealth. All investors are price takers and each one's behavior could pose marginal effect on security price in completely competitive market. Given single period investment, all investors could plan their own investment portfolio of all publicly traded financial assets and any asset that could be lent or borrowed at fixed free interest rate (Bai et al, 2019) ${ }^{[1]}$. Since all investors master Markowitz securities investment portfolio theory, they have homogeneous expectations on securities expected return, standard deviation, covariance and economic conditions. All investors have the same expected return vector and covariance matrix (Bai et al, 2019). Then, there is a single frontier border and single efficient frontier. Given allowance of short selling, investors could invest in risky assets by funds from short selling assets. Adding risk free assets to the risky assets portfolio forms a new portfolio and increasing investment opportunities greatly change original efficient frontier. Thus, the optimal portfolio changes and the new efficient frontier is a straight line.

CAL reveals equilibrium relationship between expected return and standard deviation of efficient investment portfolios $^{[2]}$. Single risky security itself is an ineffective portfolio always under CAL. SML confirms equilibrium relationship between single securities expected return and portfolio covariance (Mishra and O'brien, 2019). SML contains all securities and all portfolios. Thus, SML contains market portfolios and risk free assets. Since expected return is negatively correlated to security price, risky asset pricing formula is giving as following.

$$
\begin{gathered}
\mathrm{E}\left(R_{i}\right)=R_{f}+\left[\mathrm{E}\left(R_{M}\right)-R_{f}\right] * \beta_{i M} \\
\beta_{i M}=\frac{\operatorname{cov}\left(R_{i}, R_{m}\right)}{\sigma_{M}^{2}}
\end{gathered}
$$

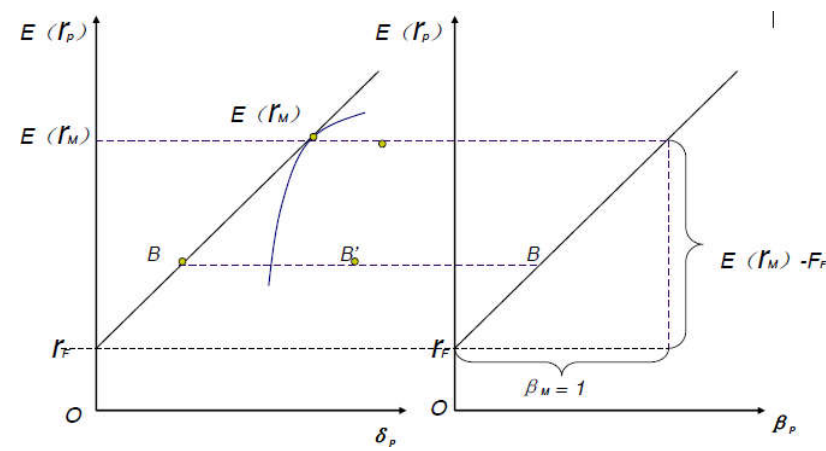

For single security, random return satisfies following functions.

$$
\begin{gathered}
r_{i}=r_{f}+\beta_{i M} *\left(r_{M}-r_{f}\right)+e_{i} \\
e_{i}=\operatorname{cov}\left(e_{i}, r_{m}\right)=0
\end{gathered}
$$

Investment portfolio i risk is divided into diversified risk and systematic risk.

$$
\sigma_{i}^{2}=\beta_{i m}^{2} * \sigma_{m}^{2}+\operatorname{var}(e)
$$

Using CML could price arbitrary security.

$$
\mathrm{E}\left(r_{i}\right)=r_{f}+\frac{E\left(r_{m}-r_{f}\right)}{\sigma_{m}} * \sigma_{i}=\frac{E\left(r_{m}\right)-r_{f}}{\sigma_{m}} * \beta_{i m} * \sigma_{m}=r_{f}+\beta_{i m} *\left[E\left(r_{m}\right)-r_{f}\right]
$$

$E\left(\tilde{r}_{q}\right)=E\left(\tilde{r}_{z c m}\right)+\beta_{q m}\left[E\left(\tilde{r}_{m}\right)-E\left(\tilde{r}_{z c m}\right)\right], r_{i} \leq E\left(\tilde{r}_{z c m}\right) \leq r_{b}$

$E\left(\tilde{r}_{q}\right)=E\left(\tilde{r}_{z c l}\right)+\beta_{q e}\left[E\left(\tilde{r}_{i}\right)-E\left(\tilde{r}_{z c t}\right)\right]=r_{i}+\beta_{q e}\left[E\left(\tilde{r}_{e}\right)-r_{i}\right]$

$E\left(\tilde{r}_{q}\right)=E\left(\tilde{r}_{z c B}\right)+\beta_{q e^{\prime}}\left[E\left(\tilde{r}_{B}\right)-E\left(\tilde{r}_{z c B}\right)\right]=r_{B}+\beta_{q e^{\prime}}\left[E\left(\tilde{r}_{e^{\prime}}\right)-r_{B}\right]$

CAPM implies pricing any investment portfolio that for any investment portfolio q, any investment portfolio on the upper frontier and zero covariance portfolio, particularly market portfolio and a portfolio zcm or tangible portfolio e and $\mathrm{L}$, pricing formulas are:

\section{CAPM's Empirical Problems May Reflect Theoretical Failings, the Result of Many Sim- plifying Assumptions}

CAPM's empirical weaknesses are reflected in application in investment assessment. In the first place, beta of the project itself is not equivalent to corporate

beta and the two coefficients have to be separated. A way to differentiate the two coefficients is that company beta is regarded as beta of different activities, weighted average of fair value of related assets in the activity (Campbell et al, 2018). However, it is hard to obtain the fair value through different types investment activities. Another difficulty is that corporate capital structure is hard to access in order to calculate related gearing ratio. For instance, many of companies have relatively complicated capital structure, namely, its have different corporate financing methods (Campbell et al, 2018) ${ }^{[3]}$. At the same time, some companies are likely to have bond funds raised in non-public market or using complicated financing methods, such as convertible bonds (Abdoh and Varela, 2018). Besides, in order to simplify calculation, it is assumed that beta coefficient is zero, this assumption is likely to raise uncertainty of discount rate of the project.

When CAPM is used to evaluate project investment, there is an assumption that regulated investment period is one year. Although this assumption is convenient for data comparison, this assumption is far from empirical evidence that actual investment is usually crossing standard periods. The biggest problem of CAPM in empirical study is that fluctuation is defined as risk (Sanghera, 2010) ${ }^{[4]}$. This practice misleads many people. Asset fluctuation is 
fluctuation itself and risk refers to the possibility of not reaching expected return. Fluctuating asset is not necessarily risky and diversification makes it not a problematic issue (Sanghera, 2010) ${ }^{[5]}$. Investment portfolio theory uses irrelevance of assets. In this way, return could be raised given the same uncertainty or portfolio fluctuation could be lowered given low rate of return.

In empirical study, if we use monthly data to do research, beta could not be accurately assessed because of short time span and market value effect. If using monthly data to estimate beta, no matter in economic sense or statistical sense, beta has been turned effective. In empirical study, from long-term perspective of CAPM, CAPM makes sense. For such equilibrium model, only in long term, its constraints occur (Sanghera, 2010). CAPM is fundamentally a long-term problem. Thus, many research studies use short-term data and generate totally opposite conclusions against CAPM. As pointed by Jagannathan and McGrattan (1995), academic circle is keen on linear relationship between short-term risk and expected return and its circulations. But in long run, CAPM effectiveness has been proved ${ }^{[6]}$. For instance, in empirical study done by Ang and Chen (2007), they used annual data from 1926 to 2001 and research conclusion is effective to support CAPM definitely beta keeps changing. Some other empirical studies could defuse Fama and French's criticism of CAPM. For example, empirical study by Amihud in 1993, they use GLM instead of OLS methods to re- calculate and they found that beta still reflects asset price. Kim (2015) found that Fama's method has variable errors $^{[7]}$. Kim (2015) supported CAPM using UK data and they concluded that Fama and Fench two-step validation method mainly accounts for failure of CAPM. Kim initiated a stunning research in 2015 and he stated that CAPM is a failed reform in finance sector. However, a large portion of his statement is excessive.

CAPM core theory concentrates on existence of market portfolio that is required to include all risky assets and use market value as weighted factor. However, Roll (2012) stated that this kind of market portfolio is inaccessible. For most tests of CAPM, they are tested by using stock market index that fails to contain all stocks. This problematic issue leads to difficulty to test CAPM. However, this does not mean that CAPM is a complete failure and the problem goes to the empirical study itself. Roll (2012) stated that market model is the core of CAPM and if we cannot find such portfolio, it is a malarkey to test CAPM. From his perspective, test of CAPM has to guarantee that any arbitrary investment portfolio meets requirement of return-risk curve. This requires that all portfolios have the linear relationship between return and risk. However, Roll
(2012) casted doubt on CAPM that whether we could find a market portfolio as a benchmark. Actually, we partially acknowledge that CAPM is wrong to some extent. But the issue is that what the extent of failure is on earth or whether CAPM is always or occasionally wrong. Most perspectives claimed that CAPM is a complete failure ${ }^{[8]}$. The right way is to realize weaknesses of CAPM and we have to use CAPM carefully.

A main problem of CAPM is that we are too strict towards beta calculation. Garcia et al (2011) assumed that we live in the world that completely meets CAPM assumptions and there are merely two scenarios of CAPM, poor state and wealthy state ${ }^{[10]}$. In order to simplify discussion, they thought there were merely two stocks in the market, stock A and stock B. Their beta keeps changing in the market and risk premium keeps changing in the market. This last column lists average condition. We notice that two stocks have different beta and have the same risk premium, which is inconsistent to what CAPM defines (Garcia et al, 2011). Then, we find that no matter which state we are in, the whole market could meet requirement of CAPM. This example tells is that if beta volatility is ignored, our understanding of CAPM has trouble.

\section{Drivers of Expected Stock Returns and Various Multifactor Models to Capture These Return Patterns as Suggested by Fama and French}

Fama French three factor model is an extended version of CAPM. CAPM states that there is a positive linear relationship between expected return and market beta, and higher beta, higher asset expected return. Market beta necessarily explains for expected security asset (Boutabba, $2015)^{[11]}$. However, Eugene Fama and Kenneth French added two factors to CAPM, namely SMB also referred to size factor, and HML, book to market factor, also called value factor. They claimed that market factor, SMB and HML could better explain for asset weighted average return. When CAPM has been raised, many researchers found that beta could not completely account for expected asset return.

Some empirical studies show that size, book to market ratio, leverage ratio and $\mathrm{E} / \mathrm{P}$ could well explain for stock return (Boutabba, 2015) ${ }^{[12]}$. However, CAPM could not explain for these abnormalities. Thus, Fama and French published an article in 1992 as a synthesizer of further improvement of CAPM. They took these factors into consideration and did research on stocks publicly traded on NYSE, AMEX and NASDAQ during the period from 1963 to 1990 besides financial stocks about how their average 
weighted return relates to these factors.

In cross-section regression model, the four factors showed strong accountability for average weighted return. In multi-factor linear regression, market value and book value have accountability of the other two factors in explanation of weighted average return and evolve as decisive variables of explaining for average return (Trigeorgis and Lambertides, 2014 ${ }^{[13]}$. In 1993, Fama and French published another article Common Risk Factors in Returns on Stocks and Bonds as a benchmark of establishment of three factor model. In this literary works, they illustrate that three factors could better explain for weighted average stock returns and intercept of regression analysis is approaching to zero. This implies that market factor, size factor and the ratio of book to value market value together explain for stock returns.

Fama French three factor model is listed as following.

$E(R i t)-R f t=\beta i[E(R m t-R f t)]+\operatorname{siE}(S M B t)+h i E(H M I t)$

$R f t$ refers to risk fre rate of return at time $\mathrm{t}$

$R m t$ refers to market rate of return at time $\mathrm{t}$

Rit is return of asset $\mathrm{i}$ at time $\mathrm{t}$

$E(R m t)-R f t$ is risk premium

$S M B t$ is a size factor short for simulated small minus big rate of return at time $\mathrm{t}$

HMIt is short for high minus low rate of return, book to market value ratio at time $t$ beta, si and hi are coefficients of three factors

regression model is listed as following.

$$
R i t-R f t=a i+\beta i(R m t-R f t)+S i S M B t+h i H M I t+\varepsilon i t
$$

However, we are consciously aware of the fact that the three-factor model does not mean completeness of capital asset pricing model. In empirical studies, there are some omitted factors in three factor model, including short term reversion, medium term momentum, fluctuation, skewness and gambling (Trigeorgis and Lambertides, 2014) ${ }^{[14]}$.

Fama and French examined returns of publicly traded stock on NYSE, AMEX and NASDAQ in spite of financial stocks. They categorized stocks into ten groups by market value and divide each market value portfolio into ten squads by beta. And then a hundred of stock portfolios are given. As shown in table 1, in horizontal sense, beta value increases from left to right, from low to high. In vertical sense, from up to bottom, market value increases, from small to large. The number in table 1 represents monthly return of each investment portfolio. Then, we could see a phenomenon that is against what we have learned from CAPM that for each investment portfolio, beta in each column is not equal. However, CAPM states that beta is the single factor that accounts for stock return, which is equivalent to the statement that is beta equals, stock return is the same. As market value decreases, stock return goes up (Clark and Kassimatis, 2011). That is to say, for each group, beta, small market value stocks witnessed greater return than stocks of large market value.

\section{Table 1}

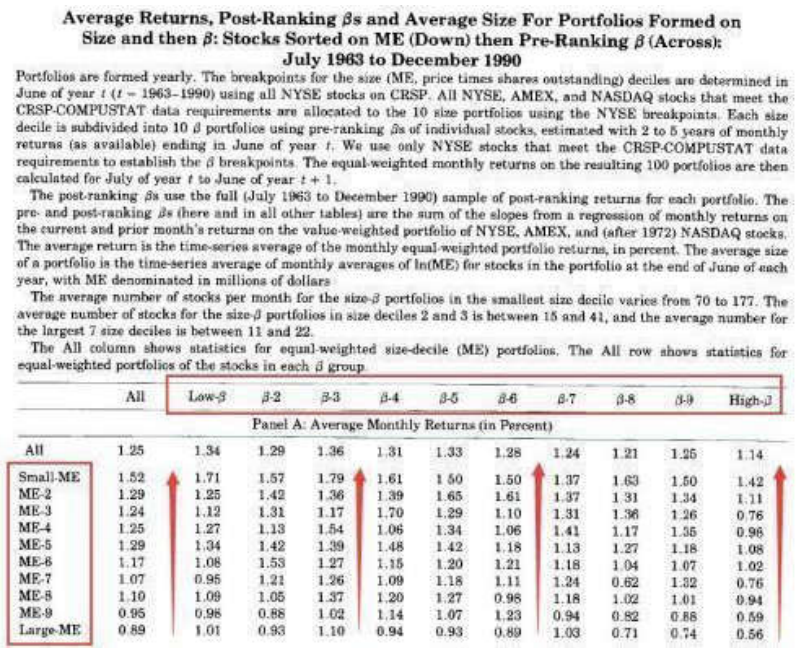

As for book to market value ratio, same stocks are divided into ten groups. As for their return, in horizontal sense, from left to right, market value ratio increases and return goes up. However, this is not completely owed to beta. As shown in beta column, there is insignificant difference, which is equivalent to the statement that given insignificance of beta, those stocks of higher book to market value ratio, witnessed higher returns (Clark and Kassimatis, 2011). This is against what CAPM tells.

Table 2

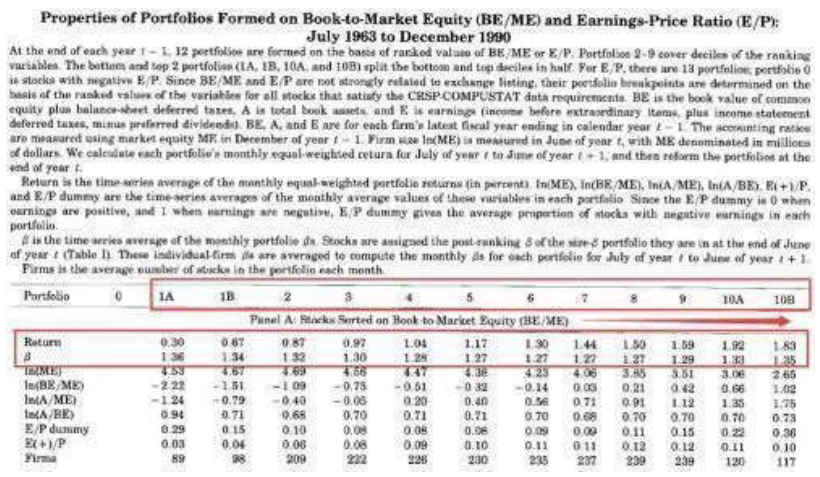

At last, they divided stocks into ten groups by market value and divide each group into ten segments in comparison (Clark and Kassimatis, 2011) ${ }^{[15]}$. As following table shows, from left to right, market value increases from low to high and increases from up to down, small to large. It is obvious that the stock portfolios in top right corner of table $\mathrm{V}$, their return is much higher than others. The stock port- 
folios feature small market value and high book value.

Table 3

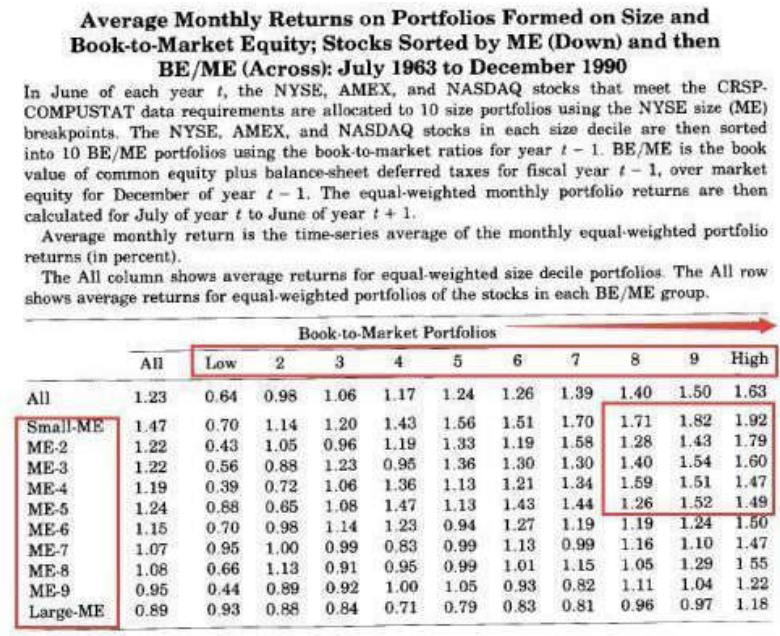

Thus, in statistical sense, we could conclude that market beta at least not capable of explaining for stock returns differential, while market value and book value are two persuasive factors in explanation of weighted average return of stock portfolios.

\section{Exante Cost of Equity in Analyst' Earnings Forecasts and Stock Prices to Overcome the Limitations Associated with Using Traditional Asset Pricing Models Stock Dividend Growth Model}

\section{Calculation function is $\mathrm{K}=\mathrm{D} / \mathrm{P}+\mathrm{G}$}

Where $\mathrm{K}$ is cost of equity, $\mathrm{D}$ is expected annual stock dividend, $\mathrm{P}$ is normal stock price and $\mathrm{G}$ is normal stock dividend growth rate.

Related data could be found in annual financial statement by trend analysis and linear regression analysis. If common stocks have financing cost when issuing, the calculation function has to deduct financing expense.

Calculation function is $\mathrm{K}=\mathrm{D} / \mathrm{P}^{*}(1-\mathrm{f})+\mathrm{G}$ where $\mathrm{f}$ is financing cost ratio.

$$
V=\sum_{t=1}^{\infty} \frac{D_{t}}{(1+k)^{2}}
$$

Where $\mathrm{V}$ is internal value of each stock, Dt is expected stock dividend value at time $\mathrm{t}$, and $\mathrm{k}$ is expected discount rate or expected rate of return.

The calculation function shows that stock internal value is the aggregate of discounted present value of future cash flows (Yagil, 1986). According to special dividend payout method, DDM model has some simplified versions of functions.

\subsection{Zero Dividend Growth Model}

Given circumstance of zero dividend growth, future dividend payment is fixed amount. Calculation function is $\mathrm{V}=\mathrm{D} 0 / \mathrm{k}$ where $\mathrm{V}$ is corporate value, $\mathrm{D} 0$ is current stock dividend and $\mathrm{K}$ is investors' required rate of return or cost of capital (Yagil, 1986).

\subsection{Permanent Dividend Growth Model}

If stock dividend growth is $\mathrm{g}$, calculation function is $\mathrm{V}=\mathrm{D} 1 /(\mathrm{k}-\mathrm{g})$ where $\mathrm{D} 1=\mathrm{D} 0(1+\mathrm{g})$ is stock dividend of next round rather than current stock dividend.

If dividend growth rate changes, the calculation function could evolve as two periods, three periods and multi period dividend growth models. The two period dividend growth model assumes that at time 1, stock dividend grows at g1 and then stock dividend growth rate turns to g2 after the first period (Cornell, 1999) ${ }^{[16]}$. The three-period dividend growth model is quite similar as the two-period stock dividend model but for an extra time point and an extra growth rate of $\mathrm{g} 3$.

Stock price is determined by supply and demand in market economy. Stock price does not necessarily reflect real intrinsic value of the corporation but fully reflected in the company's continuing business operation (Cornell, 1999). Thus, corporate stock value is decided by stock dividends paid annually. Then, the amount of stock dividend is directly related to business operation. Stock intrinsic value is directly decided by the company's business performance (Cornell, 1999). It is of great importance in reality to doing research on a company's intrinsic value to make strategic investment decision. This DDM has positive meaning of overcoming partial weaknesses of conventional capital asset pricing model (Cornell, 1999) $)^{[17]}$.

\subsection{Discount Cash Flow Model (DCF)}

$$
P=\sum_{t=1}^{n} \frac{C_{t}}{(1+r)^{t}}
$$

P refers to corporate value, $\mathrm{n}$ is the company's operation life, CFt is cash flow at time $t$ and $r$ reflects discount rate of expected cash flows.

DCF model has an advantage that the result reflects intrinsic value of the company by calculating discounted free cash flows. DCF model is the most reasonable valuation technique. A weakness of DCF model is that future cash flow cannot be confirmed accurately and the calcu- 
lated result is greatly affected by discount rate (Cornell, 1999).

\section{Conclusion}

In brief summary, we partially acknowledge that CAPM is wrong to some extent. But the issue is that what the extent of failure is on earth or whether CAPM is always or occasionally wrong. Most perspectives claimed that CAPM is a complete failure. The right way is to realize weaknesses of CAPM and we have to use CAPM carefully. Fama French three factor model has a severe weakness. Market beta at least not capable of explaining for stock returns differential, while market value and book value are two persuasive factors in explanation of weighted average return of stock portfolios.

\section{References}

[1] Abdoh, H. and Varela, O., 2018. Competition and exposure of returns to the C-CAPM, Studies in Economics and Finance, 35(4), pp.525-541.

[2] Ang, A. and Chen, J., 2007. CAPM over the long run: 1926-2001, Journal of Empirical Finance, 14(1), pp.1-40.

[3] Anon, A., 2005. CAPM over the long run: 19262001, Cambridge, Mass: National Bureau of Economic Research.

[4] Bai, H., Hou, K., Kung, H., Li, H., Erica, X.N. and Zhang, L. 2019. The CAPM strikes back? An equilibrium model with disasters, Journal of Financial Economics, 131(2), pp.269-298.

[5] Boutabba, I., 2015. An empirical validation of Fama and French Three-Factor Model on some U.S indices, Asian Economic and Financial Review, 5(7), pp.915925.

[6] Campbell, J.Y., Giglio, S., Polk, C. and Turley, R., 2018. An intertemporal CAPM with stochastic volatility. Journal of Financial Economics, 128(2), pp.207-233.
[7] Clark, E. and Kassimatis, K., 2011. An alternative measure of the "world market portfolio": Determinants, efficiency, and information content, Journal of International Money and Finance, 30(5), pp.724-748.

[8] Cornell, B., 1999. The equity risk premium: the longrun future of the stock market, New York: Wiley.

[9] Garcia, F.G., Filho, E.T. \& Moreiras, L.M., 2011. The empirical review test of conditional CAPM using expected returns of Brazilian, Argentinean, Portugal and United States of American portfolio. International Journal of Business Research, 11(1), pp.73.

[10] Jagannathan, R. \& McGrattan, E.R., 1995. The CAPM debate. Federal Reserve Bank of Minneapolis quarterly review, 19(4), pp.2-17.

[11] Kim, J.H., 2015. Market sentiment and the Fama-French factor premia. Economics Letters, 136(1), pp.129-132.

[12] Mishra, M. \& O’brien, T.J., 2019. Fama-French, CAPM, and implied cost of equity. Journal of Economics and Business, 101(1), pp.73-85.

[13] Roll, R., 2012. A new perspective on the validity of the CAPM still alive and well. Journal of investment management: JOIM, 10(3), pp.9-20.

[14] Sanghera, P., 2010. CAPM in depth: certified associate in project management study guide for the CAPM exam, Boston, MA: Course Technology Cengage Learning.

[15] Trigeorgis, L. and Lambertides, N., 2014. The role of growth options in explaining stock returns, Journal of Financial and Quantitative Analysis, 49(3), pp.749771.

[16] Xiao, Y., Fall, R. and Min, B.K., 2017. The financial performance of socially responsible investments: insights from the intertemporal CAPM. Journal of Business Ethics, 146(2), pp.353-364.

[17] Yagil, J., 1986. Growth, risk and the yield on common stocks in the context of the dividend-growth model, Journal of Business Finance and Accounting, 13(2), pp.251. 